\title{
PET BEREAVEMENT: MENGAJARKAN KONSEP DUKA PADA ANAK
}

\author{
Risa Juliadilla \\ Fakultas Ilmu Sosial dan Budaya Universitas Gajayana Malang \\ risajuliadilla@unigamalang.ac.id
}

\begin{abstract}
Pet bereavement encounter by children is a complicated situation. Parents should not underestimate but also not exaggerate. Unfortunately, parents frequently avoid arduous discussions, such as death, the meaning of loss, and the frequent emotional manifestations of a child's grief. However, Pet Bereavement can perform by parents to teach their child with different perspectives, such as explaining that life is side by side to death and when its existence brings the newborn of other living things. The most important thing is that parents teach the concept of sadness that responds vigorously so that children can live properly. The way of explaining death to children can affect them in going through a period of grief. Unclear explanations are possibly confusing for children to understand the concept of death. Through traditional reviews, the article aims for parents to understand and respond appropriately to grief reactions according to their child's age and teaches the process of bereavement and dealing.
\end{abstract}

Keywords: Child, Pet Bereavement, Parents

\begin{abstract}
Abstrak
Ketika anak berduka atas kematian hewan peliharaanya merupakan suatu keadaan yang rumit. Orang tua hendaknya tidak meremehkan keadaan tersebut namun juga tidak melebih-lebihkan. Sayangnya orang tua seringkali menghindari diskusi topik yang sulit salah satunya adalah kematian, makna kehilangan serta manifestasi emosi yang normal dari kesedihan anak. Padahal Pet Bereavment dapat dijadikan momen, orang tua mengajarkan dengan perspektif lain misalnya menjelaskan pada anak bahwa kehidupan berdampingan dengan kematian, saat terdapat kematian maka juga ada kehidupan baru pada mahluk lain. Hal yang terpenting orang tua mengajarkan konsep kesedihan yang harus ditanggulangi dengan sehat agar anak dapat meneruskan hidupnya. Cara penjelasan mengenai kematian pada anak dapat mempengaruhi anak dalam melewati masa duka. Penjelasan yang tidak tepat berpotensi membuat bingung anak saat memahami konsep kematian. Melalui traditional review, artikel ini bertujuan agar orang tua memahami dan merespon dengan tepat reaksi duka sesuai usia anak serta mengajarkan proses berduka dan menanggulanginya.
\end{abstract}

\section{Kata Kunci: Anak, Pet Bereavement, Orang tua}




\section{PENDAHULUAN}

Hewan peliharaan memiliki peran penting dalam mikrosistem keluarga, karena anak cenderung menganggap seperti teman sebaya atau anggota keluarga. Pada umumnya hewan peliharaan memiliki usia yang lebih pendek daripada manusia, maka anak yang memelihara hewan cenderung menyaksikan beberapa peristiwa penting siklus kehidupan seperti kelahiran, penyakit serius hingga kematian ${ }^{1}$. Kematian hewan peliharaan sebagai entitas yang kehadirannya berfungsi sebagai dasar dan figur kelekatan dimana ini akan menimbulkan reaksi duka bagi pemiliknya ${ }^{2}$. Kematian hewan peliharaan dapat terjadi dengan berbagai cara kematian secara alami, misalnya penyakit tertentu, penuaan, keputusan sadar dari proses eutanasia untuk melepaskan hewan dari kesengsaraannya serta kematian secara mendadak misalnya karena kecelakaan ${ }^{3}$.

Reaksi umum yang ditunjukan oleh seorang anak saat hewan peliharaanya mati adalah sedih dan menangis. Melalui peristiwa Pet Bereavement, anak berusaha untuk mengembangkan pemahamannya mengenai fenomena misalnya kehilangan karena kematian. Reaksi yang lebih bersifat serius yang sering ditampilkan pada anak setelah kehilangan hewan peliharaan adalah kesulitan tidur, mimpi buruk mengenai hewan peliharaan, perubahan kebiasaan makan serta penarikan sosial ${ }^{4}$. Ketika anak berduka atas kematian hewan peliharaanya merupakan suatu keadaan yang rumit. Orang tua hendaknya tidak meremehkan keadaan tersebut namun juga tidak melebih-lebihkan ${ }^{5}$.

\footnotetext{
${ }^{1}$ Gail F. Melson and Aubrey H. Fine, Animals in the Lives of Children, Handbook on Animal-Assisted Therapy, vol. 2008, 2010, https://doi.org/10.1016/B978-0-12-381453-1.10012-1.

${ }^{2}$ Sigal Zilcha-Mano, Mario Mikulincer, and Phillip R. Shaver, "An Attachment Perspective on Human-Pet Relationships: Conceptualization and Assessment of Pet Attachment Orientations," Journal of Research in Personality 45, no. 4 (2011): 345-57, https://doi.org/10.1016/j.jrp.2011.04.001.

${ }^{3}$ Charles A. Corr, "Pet Loss in Death-Related Literature for Children," Omega (United States) 48, no. 4 (2004): 399-414, https://doi.org/10.2190/HXQY-DU5D-YC39-XKJ9.

${ }^{4}$ A Chill, "The Grief Process in Children Reflection: For the Love of Looie," in When a Family Pet Dies A Guide to Dealing with Children's Loss, ed. JoAnn Tuzeo-Jarolmen (London and Philadelphia: Jessica Kingsley Publishers, 2005).

${ }^{5}$ Mary Ann Sontag Bowman, "Final Gifts: Lessons Children Can Learn from Dogs about End-of-Life, Loss, and Grief," Children, Dogs and Education: Caring for, Learning Alongside, and Gaining Support from Canine Companions, 2018, 131-49, https://doi.org/10.1007/978-3-319-77845-7_7.
} 
Masih banyak yang belum menganggap kematian hewan peliharaan tidak terlalu penting. Kalimat yang sering dikeluarkan untuk menenangkan anak adalah:

"Itu hanya hewan"

"Nanti bisa beli kucing lagi"

Sudah jangan nangis!, malu! itu hanya kelinci”,

Secara norma sosial, duka kematian hewan peliharaan tidak seperti kehilangan pada manusia. Hal ini mengakibatkan orang merasa tidak yakin dan enggan untuk mengungkapkan kesedihannya pada orang lain karena khawatir kesedihannya dianggap abnormal ataupun kekanakan ${ }^{6}$. Dukungan keluarga selama masa kesedihan sangat mempengaruhi anak mengatasi keadaaan hal tersebut. Kurangnya dukungan orang tua saat anak berduka karena kematian hewan peliharaan merupakan salah satu contoh bagaimana kesedihan terlarang untuk anak ${ }^{7}$. Anak mungkin belum mengerti mengenai konsep kehilangan yang disebabkan kematian ${ }^{8}$. Anak yang tidak dapat mengerti konsep kematian dengan benar dan sulit menerimanya mempunyai efek dalam melanjutkan hidup. Cara penjelasan mengenai kematian pada anak dapat mempengaruhi anak dalam melewati masa duka. Penjelasan yang tidak tepat dapat berpotensi membuat anak bingung saat memahami konsep kematian ${ }^{9}$.

Pet Bereavement dapat dijadikan momen bagi orang tua untuk mengajarkan dengan perspektif lain pada anak misalnya menjelaskan mengenai kematian dari sisi spiritual dan religiusitas ${ }^{10}$. Orang tua dapat memberi pengertian bahwa kehidupan berdampingan dengan kematian, saat terdapat kematian maka juga ada kehidupan baru

\footnotetext{
${ }^{6}$ S.J Parkin, “Experiencing Pet Loss as a Child: A Parental Perspective” (Edith Cowan University, 2008).

${ }^{7}$ Nora Schuurman, "Experiences of Pet Death in Childhood Memories," in Research Handbook on Childhoodnature Assemblages of Childhood and Nature Research, ed. Amy Cutter-mackenzie-knowles, Karen Malone, and E.B Hacking (Switzerland: Springer, 2020), https://doi.org/https://doi.org/10.1007/978-3-31967286-1.

${ }^{8}$ K.S Nguyen, S.P \& Rosengren, "Parental Reports of Children's Biological Knowledge and Misconceptions," International Journal of Behavioural Development 28 (2004): 411-20.

${ }^{9}$ (Nguyen \& Rosengren, 2004)

${ }^{10}$ Karl S. Rosengren, Isabel T. Gutiérrez, and Stevie S. Schein, "IV. Cognitive Dimensions of Death in Context," Monographs of the Society for Research in Child Development 79, no. 1 (2014): 62-82, https://doi.org/10.1111/mono.12079.
} 
pada mahluk lain ${ }^{11}$. Hal yang terpenting orang tua mengajarkan konsep kesedihan yang harus ditanggulangi dengan sehat agar anak dapat meneruskan hidupnya. Jelas terlihat dukungan keluarga dapat mengurangi beban pada anak selama berduka.

Sayangnya orang tua seringkali tidak memenuhi kebutuhan anak yang sedang berduka dengan menghindari diskusi topik yang sulit misalnya tentang kematian, makna kehilangan serta manifestasi emosi yang normal dari kesedihan anak. Anak biasanya tidak mampu untuk mengekpresikan emosi kesedihan dan hal ini membuat sulit orang tua ketika mengenali kesedihan $\operatorname{anak}^{12}$. Bila orang tua mengabaikan emosi serta pengalaman kedukaan pada anak maka sama saja mengabaikan dampak negatif dari kedukaan.

Setiap individu mempunyai reaksi berduka yang berbeda, biasanya kedukaan berlangsung 1 hingga 12 bulan pasca kematian, dengan durasi rata-rata 10 bulan. Individu yang mengalami duka cita normal dengan dapat menerima kehilangan dan menanggulangi kesedihannya sebanyak 80-90\%, sedangkan 10-20\% mengalami duka cita yang patologis ${ }^{13}$. Duka patologis termanifestasikan pada kecemasan, depresi dan lainnya ${ }^{14}$. Duka cita patologis karena hewan peliharaan tergolong rendah dengan nilai $4,3 \%-12 \%$ namun efek kehilangan hewan peliharaan pada anak tidak dapat disepelekan. Kesejahteraan emosional anak dan kemampuan membentuk keterikatan pada masa depan di tentukan oleh pengalaman dalam hubungan pribadi awal salah satunya adalah interaksi hewan peliharaan dengan keluarga ${ }^{15}$. Sepatutnya dampak reaksi duka cita dari Pet Bereavement mendapatkan perhatian yang mendalam di bidang psikologi. Artikel ini bertujuan agar orang tua memahami dan merespon dengan tepat reaksi duka sesuai usia anak serta mengajarkan proses berduka dan menanggulanginya melalui peristiwa Pet Bereavement.

\footnotetext{
${ }^{11} \mathrm{~N}$ Endenburg and B Baarda, "The Role of Pets in Enhancing Human Well-Being: Effects on Child Development," in The Waltham Book of Human-Animal Interaction: Benefits and Responsibilities of Pet Ownership, ed. Robinson. I, 1st ed. (Melton Mowbray: Waltham Centre For Pet Nutrition, 1995), 7-17.

${ }^{12}$ Bowman, "Final Gifts: Lessons Children Can Learn from Dogs about End-of-Life, Loss, and Grief."

${ }^{13}$ (Wrobel \& Dye, 2009)

${ }^{14}$ Donna Podrazik et al., "The Death of a Pet: Implications for Loss and Bereavement across the Lifespan," Journal of Personal and Interpersonal Loss 5, no. 4 (2000): 361-95, https://doi.org/10.1080/10811440008407852.

${ }^{15}$ Parkin, "Experiencing Pet Loss as a Child: A Parental Perspective."
} 


\section{METODE PENELITIAN}

Metode yang digunakan adalah traditional review, dimana penulis melakukan pencarian artikel yang sesuai dengan berbagai kata kunci pet bereavement, pet griefing serta pet loss. Penulis juga menelusuri bagaimana konsep kematian pada pemahaman anak lalu penulis mensitesis secara naratif.

\section{HASIL PENELITIAN DAN PEMBAHASAN}

Untuk mampu memahami efek akibat kehilangan hewan peliharaan, maka kita harus memahami dulu sifat keterikatan manusia dan hewan. Bagi anak, hewan peliharaan dianggap mampu menyediakan dukungan, kasih sayang saat manusia lain tidak menyediakan, tidak mampu dan enggan ${ }^{16}$. Berdasarkan teori kelekatan dari Bowlby, hewan peliharaan juga dapat memberikan ikatan emosional yang menawarkan rasa aman dan kesejahteraan serta bersifat tanpa syarat dan memberikan perasaan tidak menghakimi. Saat pemilik hewan membentuk ikatan yang kuat dengan hewannya maka sangat wajar itu berdampak pada kesejahteraan emosional. Semakin dalam keterikatannya dengan hewan peliharaan maka semakin kuat reaksi kesedihannya ${ }^{17}$

Anak lebih berduka daripada orang dewasa pada saat kehilangan hewan peliharaan. Bowlby menyatakan anak memiliki kapasitas untuk berduka lebih dalam karena mereka tidak mampu untuk mengekpresikan perasaannya secara terbuka. Berbeda halnya dengan orang dewasa. Perbedaan yang terlihat pada proses berduka pada anak dan orang dewasa adalah anak cenderung menarik diri dan kurang mampu menunjukkan emosi mereka ${ }^{18}$.

Anak memiliki kapasitas terbatas untuk menoleransi rasa sakit psikologis akibat kehilangan. Respon seorang anak menanggapi kehilangan hewan peliharaan terkait dengan tingkat keterikatan, tingkat perkembangan kognitif, serta dukungan yang tersedia untuk anak. Jenis kelamin anak dalam merespon kematian hewan peliharaan juga

\footnotetext{
${ }^{16}$ Melson and Fine, Animals in the Lives of Children.

${ }^{17}$ Bruce S. Sharkin and Donna Knox, "Pet Loss: Issues and Implications for the Psychologist," Professional Psychology: Research and Practice 34, no. 4 (2003): 414-21, https://doi.org/10.1037/0735-7028.34.4.414.

${ }^{18}$ Jo Ann Jarolmen, "A Comparison of the Grief Reaction of Children and Adults: Focusing on Pet Loss and Bereavement," Omega 37, no. 2 (1998): 133-50, https://doi.org/10.2190/H937-U230-X7D9-CVKH.
} 
berpengaruh. Dilaporkan bahwa perempuan lebih merasakan kesedihan terhadap kehilangan hewan peliharaan daripada laki-laki ${ }^{19}$. Setiap anak memiliki reaksi emosional yang berbeda pada kematian, hal ini juga ditentukan kelompok usia dalam melakukan koping. Reaksi khas pada kehilangan hewan peliharaan diberbagai usia anak adalah:

1. Anak usia $1-3$ tahun

Dalam usia ini, anak belum memiliki pemahaman tentang kematian secara permanen. Mereka sering mengibaratkan kematian sebagai bentuk tidur. Kesedihan terwujudkan dengan tangisan dan mencari sosok attachement yang hilang. Mereka mungkin masih mencari hewan peliharaan atau memanggil hewan peliharaanya.

Hal yang harus dilakukan adalah mendampingi mereka dan memvalidasi perasaan yang mereka rasakan. Orang tua dengan perlahan memberitahu bahwa sedih itu merupakan hal yang normal. Memberitahukan kenyataan bahwa hewan peliharaan memang sudah tidak ada namun masih terdapat dukungan keluarga lainnya. Sebuah pelukan dan kenyamanan merupakan hal yang membantu anak dalam menghadapi kedukaan ${ }^{20}$.

2. Anak usia 4-6 tahun,

Pada usia ini, anak memahami bahwa hewan peliharaan secara fisik hidup di tempat lain seperti di langit atau di surga. Namun mereka belum memiliki konsep apa dan dimana surga berada. Anak pada tingkat usia ini belum tahu penyebab kematian sehingga mereka menanyakan pada diri mereka diri sendiri dan seringkali anak tidak membicarakan hal ini $^{21}$. Dalam pikiran anak, hewan peliharaan akan hidup di tempat lain untuk makan, bermain dan tidur. Keyakinan ini dibentuk oleh pengalaman sebelumnya kematian anggota keluarga dan penjelasan oleh orang tua. Anak sadar bahwa tidak bisa lagi beraktivitas dengan hewan peliharannya seperti memberi makan, bermain atau tidur dengan hewan peliharaan. Situasi ini menyebabkan perasaan kesepian. Orang tua baiknya tidak memarahi anak namun menyarankan

\footnotetext{
${ }^{19}$ (Brown, \& Richards, 1996)

${ }^{20}$ Michael Ardizzone, "Signs and Symptoms of Grief in Children Reflection: A Sudden Death and Longstanding Grief," in When a Family Pet Dies A Guide to Dealing with Children's Loss, ed. JoAnn Tuzeo-Jarolmen (London and Philadelphia: Jessica Kingsley Publishers, 2007), 31-42.

${ }^{21}$ Ardizzone.
} 
agar anak membagikan perasaannya. Mengekpresikan apa yang dirasakan anak juga bisa dilakukan melalui media lain misalnya menggambar mengenai kenangan bersama hewan peliharaannya. Biarkan anak juga megekpresikan mengenai apa yang dirasakan serta mengenang hewan peliharaanya.

3. Anak Usia 7-9 tahun

Pada usia ini menganggap kematian adalah hal yang final. Anak pada periode ini menganggap dunia sebagai tempat aman. Dimana mereka bisa bermain, mempunyai teman dan bersekolah. Kehilangan hewan peliharaan dapat menjadi hal yang traumatis, mereka dapat menarik diri dari kegiatan. Saat lingkungan sekitarnya tidak dapat memahami maka terwujud perilaku agresif pada teman sebaya dan saudara kandung $^{22}$. Kelompok usia ini, anak sering mempercayai jika mereka tidak akan mati pada saat itu, namun mereka lebih memikirkan mengenai orangtuanya. Kelompok usia ini menjadi terikat dan bergantung pada orang tuanya. Seringkali kesedihan yang dirasakan oleh anak menjadi periode yang tertunda karena sulit terlibat dalam proses berkabung.

4. Anak Usia 10- 12 tahun

Dalam tahap ini anak mulai memahami kematian sebagai hal yang wajar dalam siklus kehidupan dan mulai mampu bereaksi seperti dewasa

${ }^{23}$ Mercurio \& Mc Namee menyatakan sangat penting menjelaskan kematian pada anak dengan penjelasan yang tepat, karena anak membutuhkan bantuan orang dewasa memahami bahwa hewan mereka yang telah mati tidak hidup kembali karena organ mereka yang tidak berfungsi. Orang dewasa harus menjawab secara faktual pertanyaan yang diajukan oleh anak untuk menghindari ambiguitas. Peristiwa kematian hewan peliharaan dapat dijadikan momen untuk mengajarkan tentang kehidupan sehari-hari salah satunya adalah mengajarkan konsep kedukaan karena kematian. Orang tua dapat mendiskusikan dengan anak tentang bagaimana dan mengapa kematian terjadi ${ }^{24}$. Diskusi ini dapat disisipkan nilai, kepercayaan, keyakinan dan spiritual. Pemahaman anak tentang kematian sangat dipengaruhi oleh keyakinan atau agama. Peran orang tua menjadi

\footnotetext{
${ }^{22}$ Ardizzone.

${ }^{23}$ Mercurio \& Mc Namee (2006)

${ }^{24}$ Lee, Lee, \& Moon, (2009)
} 
panutan anak dalam menghadapi situasi duka misalnya mengucapkan turut berduka cita saat mendengar kematian, bagaimana berperilaku saat prosesi pemakaman dan bagaimana mengikhlaskan saat di tinggal pergi oleh sesuatu yang kita sayangi. Hal lain yang dapat dipelajari adalah keterampilan dasar dalam memberi dukungan emosional dengan orang lain pada saat suasana berduka. Anak dapat mengimitasi ekpresi, perilaku orang dewasa kepada orang yang sedang berduka ${ }^{25}$.

Baker, Sedney \& Gross menyatakan proses berduka bagi anak sebagai serangkaian tugas. Diawali dengan tugas utama, ketika anak memahami bahwa seseorang yang telah meninggal dengan menyodorkan banyak pertanyaan, melihat reaksi orang lain, yang terkadang reaksi tersebut merupakan penolakan, maupun isolasi untuk melindungi diri dari perasaan duka. Tugas tengah adalah mengakui realitas kehilangan, mengevaluasi kembali hubungan dengan seseorang atau sesuatu yang telah tiada, mengatasi tekanan emosional serta penerimaan kehilangan ${ }^{26}$

Tugas akhir adalah anak harus mengembangkan rasa hubungan baru tanpa dilanda rasa takut kehilangan yang berlebihan. Teori menyatakan setiap anak harus melalui tahapan ini untuk mencapai kehidupan yang normal. Setelah menyelesaikan semua tugas sebelumnya, anak dapat melanjutkan tugas perkembangan yang sempat terganggu oleh kesedihan serta belajar bagaimana menghadapi perasaan sedih. Hal ini bertujuan untuk mempersiapkan kejadian mengenai siklus kehidupan yang mungkin timbul di kemudian hari, seperti pada hari ulang tahun atau kematian.

Cara kematian hewan peliharaan juga mempengaruhi reaksi individu terhadap kehilangan. ${ }^{27}$ McCutcheon \& Fleming, menyatakan individu yang kehilangan hewan peliharaan karena penyakit alami (misalnya faktor umur) memiliki kesedihan lebih tinggi daripada pemilik hewan peliharaan yang memilih cara untuk eutanasia. Hal ini disebabkan karena mereka telah mempersiapkan kehilangan. Begitupula kematian mendadak hewan peliharaan seperti sakit atau kecelakaan memiliki reaksi kesedihan yang tinggi dibandingkan dengan kematian hewan peliharaan yang penyebab alami ataupun eutanasia.

\footnotetext{
${ }^{25}$ Bowman, "Final Gifts: Lessons Children Can Learn from Dogs about End-of-Life, Loss, and Grief."

${ }^{26}$ Parkin, (2008)

${ }^{27}$ McCutcheon \& Fleming, (2002)
} 
Quackenbush seorang tokoh yang banyak membahas mengenai Pet Bereavement, menyarankan agar tidak terlalu cepat mengganti hewan peliharaan. Hal yang lebih penting adalah bagaimana memberi waktu pada anak untuk memvalidasi perasaan duka serta kesiapan untuk kembali memelihara hewan. Ini serupa dengan mempersiapkan anak agar kembali percaya pada suatu hubungan dengan hewan peliharaan baru dan tanpa rasa takut kehilangan secara berlebihan ${ }^{28}$.

Sebuah tahapan model mengenai tahapan duka akibat kematian hewan peliharaan dari Quackenbush pada tahun 1985 menyatakan terdapat 4 tahap yaitu ${ }^{29}$ :

1. Rasa bersalah, perasaan bahwa kita telah berusaha menjaga hewan peliharaan dan merasa telah mengecewakan mereka. Saat hewan peliharaan mati, pemilik mungkin merasa tidak berdaya sehingga mencaci diri mereka sendiri.

2. Kemarahan, Kematian hewan peliharaan dapat membuat frustasi, dan kemarahan sering terjadi karena merasa tidak mampu untuk mengendalikan dan mengubah situasi. Pemilik merasa bersalah dan marah ketika hewan peliharaan mereka mati karena kecelakaan yang nampak seperti tidak masuk akal. Kemarahan juga dapat diterwujudkan marah pada orang tua ataupun dokter hewan ${ }^{30}$

3. Penolakan, seperti halnya berduka seperti kehilangan manusia perasaan sedih yang dirasakan berupa rasa tidak percaya menolak adanya kehilangan atau menunda berpikir realistis tentang apa yang terjadi

4. Depresi, hal ini ditandai dengan rasa bersalah, lesu, perasaan melankolis serta kurangnya motivasi.

Tahapan ini tidak selalu berurutan, begitu juga durasi dan intensitas tergantung dari proses individualistis. Tahapan ini mengabaikan aspek sosial, spiritual, kekeluargaan dan pengalaman pribadi individu ${ }^{31}$. Berbeda halnya, teori duka milik Kubler-Rus (1969), pada tahapan akhir terdapat tahap penerimaan. Tahap dimana mulai menerima keadaan duka dengan sehat serta melanjutkan hidup kembali. Tahap terakhir inilah yang diharapkan serta menjadi tujuan akhir pada proses berduka.

\footnotetext{
${ }^{28}$ Podrazik et al., "The Death of a Pet: Implications for Loss and Bereavement across the Lifespan."

${ }^{29}$ Parkin, "Experiencing Pet Loss as a Child: A Parental Perspective."

${ }^{30}$ Chill, "The Grief Process in Children Reflection: For the Love of Looie."

${ }^{31}$ Podrazik et al., "The Death of a Pet: Implications for Loss and Bereavement across the Lifespan."
} 
Setiap individu memiliki rentang waktu untuk berduka serta waktu untuk kembali pada kondisi sedia kala. Bila anak mulai menarik diri dari aktivitas sehari-hari untuk waktu yang cukup lama maka anak membutuhkan bantuan profesional. Konseling duka yang dilakukan oleh profesional seperti dokter dan psikolog dapat dijadikan alternatif. Salah satu hal yang menjadi perhatian utama dalam hal ini ialah dengan mengajarkan teknik koping yang sehat. Orang tua dapat diberi psikoedukasi untuk memberi penjelasan dengan bahasa yang konkret ${ }^{32}$

\section{PENUTUP}

Peristiwa Pet Bereavement dapat dijadikan kesempatan orang tua untuk mengajarkan kesedihan. Orang tua dapat memberikan bimbingan anak mengenai konsep kehilangan atau kematian pada anak baik dari berbagai aspek. Ini mungkin jauh lebih baik daripada mengajarkan anak untuk terus berlarut dalam kesedihan atau menyalahkan diri. Melalui situasi ini anak dapat belajar untuk mengkonfirmasi apa yang dirasakan, dan mengajarkan berdamai dengan kesedihan serta berusaha melaluinya dengan baik. Tak kalah pentingnya orang tua juga harus memberikan arahan mengenai kesedihan yang normal dan yang lebih penting adalah mengajarkan semangat baru pada anak.

\section{DAFTAR RUJUKAN}

Ardizzone, Michael. "Signs and Symptoms of Grief in Children Reflection: A Sudden Death and Longstanding Grief." In When a Family Pet Dies A Guide to Dealing with Children's Loss, edited by JoAnn Tuzeo-Jarolmen, 31-42. London and Philadelphia: Jessica Kingsley Publishers, 2007.

Bowman, Mary Ann Sontag. "Final Gifts: Lessons Children Can Learn from Dogs about End-of-Life, Loss, and Grief." Children, Dogs and Education: Caring for, Learning Alongside, and Gaining Support from Canine Companions, 2018, 13149. https://doi.org/10.1007/978-3-319-77845-7_7.

Brown, B. H., \& Richards, H. C. "Pet Bonding and Pet Bereavement among Adolescents." Pet Bonding and Pet Bereavement among Adolescents. 74 (1996):

\footnotetext{
${ }^{32}$ Sharkin and Knox, "Pet Loss: Issues and Implications for the Psychologist."
} 
505-9.

Chill, A. "The Grief Process in Children Reflection: For the Love of Looie." In When a Family Pet Dies A Guide to Dealing with Children's Loss, edited by JoAnn TuzeoJarolmen. London and Philadelphia: Jessica Kingsley Publishers, 2005.

Corr, Charles A. "Pet Loss in Death-Related Literature for Children." Omega (United States) 48, no. 4 (2004): 399-414. https://doi.org/10.2190/HXQY-DU5D-YC39XKJ9.

Endenburg, N, and B Baarda. "The Role of Pets in Enhancing Human Well-Being: Effects on Child Development." In The Waltham Book of Human-Animal Interaction: Benefits and Responsibilities of Pet Ownership, edited by Robinson. I, 1st ed., 7-17. Melton Mowbray: Waltham Centre For Pet Nutrition, 1995.

Jarolmen, Jo Ann. "A Comparison of the Grief Reaction of Children and Adults: Focusing on Pet Loss and Bereavement." Omega 37, no. 2 (1998): 133-50. https://doi.org/10.2190/H937-U230-X7D9-CVKH.

Lee, J., Lee, J., \& Moon, S. "Exploring Children's Understanding of Death Concepts." Asia Pacific Journal of Education 29, no. 2 (2009): 251-264.

McCutcheon, K.A., \& Fleming, S.J. "Grief Resulting from Euthanasia and Natural Death of Animals." Omega 44 (2002): 168-88.

Melson, Gail F., and Aubrey H. Fine. Animals in the Lives of Children. Handbook on Animal-Assisted Therapy. Vol. 2008, 2010. https://doi.org/10.1016/B978-0-12381453-1.10012-1.

Mercurio, M.L \& Mc Namee, A. "Healing Words, Healing Hearts: Using Children's Literature to Cope with the Loss of a Pet." Childhood Education, 82 (2006): 15361.

Nguyen, S.P \& Rosengren, K.S. "Parental Reports of Children's Biological Knowledge and Misconceptions." International Journal of Behavioural Development 28 (2004): 411-20.

Parkin, S.J. "Experiencing Pet Loss as a Child: A Parental Perspective.” Edith Cowan University, 2008.

Podrazik, Donna, Shane Shackford, Louis Becker, and Troy Heckert. "The Death of a Pet: Implications for Loss and Bereavement across the Lifespan." Journal of Personal and Interpersonal Loss 5, no. 4 (2000): 361-95. https://doi.org/10.1080/10811440008407852.

Rosengren, Karl S., Isabel T. Gutiérrez, and Stevie S. Schein. "IV. Cognitive Dimensions of Death in Context." Monographs of the Society for Research in Child Development 79, no. 1 (2014): 62-82. https://doi.org/10.1111/mono.12079. 
Schuurman, Nora. "Experiences of Pet Death in Childhood Memories." In Research Handbook on Childhoodnature Assemblages of Childhood and Nature Research, edited by Amy Cutter-mackenzie-knowles, Karen Malone, and E.B Hacking. Switzerland: Springer, 2020. https://doi.org/https://doi.org/10.1007/978-3-31967286-1.

Sharkin, Bruce S., and Donna Knox. "Pet Loss: Issues and Implications for the Psychologist." Professional Psychology: Research and Practice 34, no. 4 (2003): 414-21. https://doi.org/10.1037/0735-7028.34.4.414.

Wrobel, T. A., \& Dye, A. L. "Grieving Pet Death: Normative, Gender, and Attachment Issue.” Omega 47, no. 4 (2009): 385-93.

Zilcha-Mano, Sigal, Mario Mikulincer, and Phillip R. Shaver. "An Attachment Perspective on Human-Pet Relationships: Conceptualization and Assessment of Pet Attachment Orientations." Journal of Research in Personality 45, no. 4 (2011): 345-57. https://doi.org/10.1016/j.jrp.2011.04.001. 